\title{
Metastatic Malignant Neoplasm in the Mediastinum
}

National Cancer Institute

\section{Source}

National Cancer Institute. Metastatic Malignant Neoplasm in the Mediastinum. NCI

Thesaurus. Code C3578.

The spread of a malignant neoplasm to the mediastinum from an adjacent or distant anatomic site. 